\title{
FORMULASI DAN OPTIMASI BASIS KRIM TIPE A/M DAN AKTIVITAS ANTIOKSIDAN DAUN CEMPEDAK (Artocarpus champeden Spreng)
}

\author{
Septi Anggraini", Nur Mita, Arsyik Ibrahim \\ ${ }^{1}$ Laboratorium Penelitian dan Pengembangan Kefarmasian "Farmaka Tropis", \\ Fakultas Farmasi, Universitas Mulawarman, Samarinda \\ *Email : septifarmasi21@gmail.com
}

\begin{abstract}
Cream is a semisolid preparations containing one or more ingredients are dissolved or dispersed in both the oil in water emulsion type $(O / W)$ or water in oil $(W / O)$. Cempedak leaves (Artocarpus champeden Spreng) has antioxidant activity because it contains about $75 \%$ flavonoids from the isolated compounds. The purpose of this research is to get the best formula of cream base with varying concentrations of triethanolamine $(0.5 \%, 1 \%, 1.5 \%$ and $2 \%)$ and to determine the antioxidant activity of cempedak leaves against free radicals. Optimization is done by testing the physical stability of the cream base such as the organoleptic, $p H$, dispersive power, viscosity, emulsion type, the homogeneity and the stability testing of the temperature by using the Freez and Thaw methods. The antioxidant activity determination of ethyl acetate extracts from Cempedak leaves by using DPPH $(1,1$ Diphenyl-2-picrylhydrazyl) method. The optimization showed the best concentration of cream base is at concentration $2 \%$ of Trietanolamin and the IC50 that obtained was 4,275 ppm.
\end{abstract}

Key Word: Cream, antioxidants, Cempedak leaves

\begin{abstract}
ABSTRAK
Krim adalah sediaan semipadat yang mengandung satu atau lebih bahan obat yang terlarut atau terdispersikan baik dalam emulsi tipe minyak dalam air (M/A) atau air dalam minyak (A/M). Daun cempedak (Artocarpus champeden Spreng) memiliki aktivitas antioksidan karena mengandung senyawa flavonoid sebesar $75 \%$ dari senyawa yang terisolasi. Tujuan penelitian ini adalah untuk mendapatkan formula terbaik dari basis krim dengan memvariasikan konsentrasi Trietanolamin yaitu $0,5 \%, 1 \%, 1,5 \%$ dan $2 \%$ serta untuk mengetahui aktivitas antioksidan daun cempedak terhadap radikal bebas. Optimasi dilakukan dengan menguji stabilitas fisik basis krim meliputi organoleptis, $\mathrm{pH}$, daya sebar, viskositas, tipe emulsi, dan
\end{abstract}


homogenitas serta pengujian stabilitas fisik basis terhadap suhu dengan metode Freez and Thaw. Penentuan aktivitas antioksidan ekstrak etil asetat daun cempedak menggunakan metode DPPH (1,1-Difenil-2-Pikrilhidrazil). Hasil yang didapatkan dari optimasi basis krim yang terbaik adalah basis krim yang mengandung Trietanolamin sebesar $2 \%$ dan nilai $\mathrm{IC}_{50}$ ekstrak etil asetat daun cempedak sebagai antioksidan adalah 4,275 ppm.

Kata Kunci: Krim, antioksidan, daun cempedak

\section{PENDAHULUAN}

Krim adalah sediaan semipadat yang mengandung satu atau lebih bahan obat yang terlarut atau terdispersikan baik dalam emulsi tipe minyak dalam air (M/A) atau air dalam minyak (A/M) [1]. Krim umumnya lembut, berupa massa emulsi dari partikel yang dipadatkan dalam media cair, tidak membentuk lapisan film yang oklusif pada kulit. Krim mengandung lipid dan pelembab lain yang dapat menggantikan zat yang hilang dari kulit [2].

Cempedak merupakan salah satu jenis tanaman asli Indonesia. Produksinya tidak diketahui dengan pasti dan relatif terbatas karena penyebarannya juga terbatas. Tanaman ini hanya tumbuh di daerah yang bercurah hujan cukup besar. Tanaman cempedak umumnya hanya diusahakan sebagai tanaman pekarangan [3]. Daun cempedak memiliki kandungan senyawa triterpenoid, steroid, tanin, senyawa fenolik, dan flavonoid [4].

Metode 1,1- Difenil- 2 - Pikrilhidrazi (DPPH) adalah pengujian dekolorisasi yang mengukur kapasitas antioksidan yang bereaksi langsung dengan radikal DPPH dengan memantau penurunan absorbansi pada panjang gelombang $517 \mathrm{~nm}$ yang dihasilkan dari reduksi oleh antioksidan atau reaksi dengan radikal spesies. Kelebihan metode DPPH adalah sederhana, mudah, cepat, peka, serta memerlukan sampel yang sedikit [5].

\section{METODE PENELITIAN}

\section{Bahan}

Bahan yang digunakan dalam penelitian ini adalah daun cempedak, metanol, DPPH, n-heksan, etil asetat, asam stearat, trietanolamin, vaselin, propilenglikol, metil paraben, propil paraben, BHT, dan aquades.

\section{Peralatan}

Alat yang digunakan dalam penelitian ini adalah alat gelas, alat kaca, batang pengaduk, cawan porselin, hot plate, timbangan analitik, mikropipet $100-1000$ $\mu \mathrm{L}$, pipet tetes, vortex, labu takar gelap, tabung reaksi bertutup, rak tabung, rotary evaporator, spatel logam, corong pisah, statif dan klem, mixer, oven, kulkas, Spektrofotometer UV-Vis, $\mathrm{pH}$ meter dan Viskometer. 


\section{Prosedur}

\section{Penyiapan Sampel dan Ekstrak}

Penyiapan ekstrak dilakukan dengan cara membersihkan daun cempedak (Artocarpus champeden Spreng) dari kotoran kemudian dipotong kecil-kecil dan dimaserasi dengan menggunakan pelarut metanol, kemudian diuapkan pelarutnya dengan rotary evaporator. Setelah itu ekstrak difraksinasi dengan metode fraksinasi bertingkat menggunakan beberapa pelarut yaitu n-heksan dan etil asetat, kemudian hasil fraksi dengan pelarut etil asetat diuapkan di atas waterbath hingga menjadi ekstrak kental.

\section{Pengukuran Aktivitas Antioksidan Ekstrak Etil Asetat Daun Cempedak}

a. Pembuatan larutan stok ekstrak dan variasi konsentrasi

Ditimbang $20 \mathrm{mg}$ ekstrak etil asetat daun cempedak kemudian dilarutkan dalam $50 \mathrm{~mL}$ metanol, dihomogenkan. Dibuat variasi konsentrasi yaitu 2, 4, 6, 8, $10,12,14,16$ ppm dengan mengencerkan larutan stok 40 ppm.

b. Pembuatan larutan DPPH 40 ppm

Ditimbang 4 mg DPPH kemudian dilarutkan dalam $100 \mathrm{~mL}$ metanol hingga homogenkan.

\section{c. Pengukuran $\lambda$ maks}

Dimasukkan $2 \mathrm{~mL}$ larutan DPPH 40 ppm ke dalam tabung reaksi gelap bertutup. Ditambahkan $2 \mathrm{~mL}$ metanol. Dihomogenkan dengan vortex. Kemudian diukur $\lambda$ maks dengan panjang gelombang 400-600 $\mathrm{nm}$. Didapatkan $\lambda$ maks dan absorbansi blanko.

Tabel 1. Formula Basis Krim

\begin{tabular}{ccccc}
\hline \multirow{2}{*}{ Bahan } & \multicolumn{4}{c}{ Formula (\%) } \\
\cline { 2 - 5 } & $\mathrm{F}_{1}$ & $\mathrm{~F}_{2}$ & $\mathrm{~F}_{3}$ & $\mathrm{~F}_{4}$ \\
\hline Asam Stearat & 10 & 10 & 10 & 10 \\
Triethanolamine & 0,5 & 1 & 1,5 & 2 \\
Vaselin & 15 & 15 & 15 & 15 \\
Propilenglikol & 15 & 15 & 15 & 15 \\
Metil Paraben & 0,18 & 0,18 & 0,18 & 0,18 \\
Propil Paraben & 0,02 & 0,02 & 0,02 & 0,02 \\
Butil Hidroksitoluen & 0,1 & 0,1 & 0,1 & 0,1 \\
Aquades (ad) & 100 & 100 & 100 & 100 \\
\hline
\end{tabular}

d. Pengujian Aktivitas Antioksidan Ekstrak

Dimasukkan $2 \mathrm{~mL}$ larutan uji ke dalam tabung reaksi gelap bertutup dan ditambahkan $2 \mathrm{~mL}$ larutan DPPH. Dihomogenkan dengan vortex kemudian diukur 
absorbansi dengan menggunakan Spektrofotometer UV-Vis dengan $\lambda$ maks yang didapat.

Absorbansi yang didapat digunakan untuk menghitung persen efektivitas peredaman dengan rumus:

$$
\%=\frac{\text { AbsBlanko }-A b s U j i}{\text { AbsBlanko }} \times 100 \%
$$

\section{Pembuatan Basis Krim}

Pembuatan sediaan krim dilakukan dengan melebur fase minyak yaitu asam stearat, vaselin, propil paraben dan BHT di atas penangas air dengan suhu $70{ }^{\circ} \mathrm{C}$. Dilarutkan metil paraben dalam propilenglikol kemudian ditambahkan air dan dipanaskan hingga suhu $80{ }^{\circ} \mathrm{C}$ kemudian ditunggu hingga suhu turun ditambahkan trietanolamin. Dimasukkan fase minyak ke dalam lumpang panas kemudian ditambahkan fase air dan dimixer hingga terbentuk massa krim.

\section{Optimasi Basis}

\section{Uji Homogenitas}

Pengujian ini dilakukan dengan menggunakan mikroskop, kaca preparat dan kaca objek. Pengujian dilakukan dengan cara menimbang sejumlah krim. Krim tersebut dioleskan pada kaca objek dan ditutup dengan kaca preparat kemudian diamati jika terjadi penggumpalan atau pemisahan.

\section{Uji Daya Sebar}

Pengujian ini dilakukan dengan cara meletakkan krim di atas kaca transparan yang diletakkan di atas kertas grafik kemudian kaca tersebut ditutup dengan kaca transparan yang lain, dibiarkan selama kurang lebih 15 detik dan ditambahkan beban 10, 20, 50, 100, dan $200 \mathrm{~g}$ kemudian diamati diameter daerah yang terbentuk.

\section{Uji Tipe Emulsi}

Pengujian dilakukan dengan menggunakan metode pengenceran. Sejumlah krim diteteskan ke dalam $30 \mathrm{~mL}$ air. Krim tipe m/a akan terdistribusi secara merata pada medium air. Krim tipe a/m tidak akan terdistribusi merata pada permukaan air.

\section{Uji pH}

Pengukuran $\mathrm{pH}$ basis krim menggunakan $\mathrm{pH}$ meter. $\mathrm{pH}$ meter dikalibrasi menggunakan larutan $\mathrm{pH} 4$ dan $\mathrm{pH}$ 7. Kemudian diukur $\mathrm{pH}$ basis.

\section{Uji Viskositas}

Pengujian viskositas basis krim menggunakan viskometer Rheosys Cone and Plate dengan kecepatan $5 \mathrm{rpm}$. 


\section{Uji Stabilitas}

Pengujian stabilitas basis menggunakan metode Freez and Thaw dengan menggunakan dua suhu. Pertama basis krim disimpan pada suhu $4^{\circ} \mathrm{C}$ selama 48 jam dan dilanjutkan pada suhu $40^{\circ} \mathrm{C}$ selama 48 jam. Kemudian diamati organoleptis dan homogenitasnya. Pengujian dilakukan hingga 6 siklus.

\section{HASIL DAN PEMBAHASAN}

\section{A. Optimasi Basis}

Pengujian stabilitas basis krim bertujuan untuk mengamati kestabilan basis krim terhadap suhu penyimpanan. Metode yang digunakan adalah metode Freez and Thaw, metode ini terdiri dari satu rentang waktu penyimpanan pada suhu $4^{\circ} \mathrm{C}$ dan satu rentang waktu penyimpanan pada suhu $40^{\circ} \mathrm{C}$, dilanjutkan selama sediaan masih baik secara fisik. Sediaan dikatakan stabil jika setelah melewati 6 siklus tidak terjadi perubahan [6].

Hasil yang didapatkan berdasarkan pengamatan organoleptis adalah basis berwarna putih, berbentuk semi padat, dan berbau khas bahan, serta basis krim tidak mengalami penggumpalan setelah penyimpanan selama 6 siklus. Kesimpulannya basis krim stabil berdasarkan uji organoleptis dan homogenitas terhadap penyimpanan pada suhu $4^{\circ} \mathrm{C}$ dan $40^{\circ} \mathrm{C}$.

Pengujian daya sebar bertujuan untuk mengetahui kemampuan krim untuk menyebar di kulit. Daya sebar basis krim diukur menggunakan beban 10 g, 20 g, $50 \mathrm{~g}, 100 \mathrm{~g}$ dan $200 \mathrm{~g}$. Standar daya sebar sediaan krim berkisar $5-7 \mathrm{~cm}$. Berdasarkan hasil yang didapatkan daya sebar yang terbaik adalah daya sebar formula IV yaitu 8,73 cm (Lihat Tabel 2). Semakin besar daya sebar basis krim maka konsistensinya semakin encer.

Tabel 2. Hasil Uji Daya Sebar Basis Krim

\begin{tabular}{ccccccc}
\hline \multirow{2}{*}{ Formula } & \multicolumn{5}{c}{ Daya Sebar $(\mathrm{cm})$} & \multirow{2}{*}{ Rata-Rata } \\
\cline { 2 - 5 } & $10 \mathrm{~g}$ & $20 \mathrm{~g}$ & $50 \mathrm{~g}$ & $100 \mathrm{~g}$ & $200 \mathrm{~g}$ & \\
\hline I & 10,20 & 10,68 & 10,98 & 11,2 & 11,38 & 10,88 \\
II & 10,62 & 11,28 & 11,68 & 12,02 & 12,28 & 11,57 \\
III & 9,94 & 10,40 & 10,62 & 10,88 & 11,08 & 10,58 \\
IV & 8,04 & 8,46 & 8,80 & 9,04 & 9,30 & 8,73 \\
\hline
\end{tabular}

Pengujian tipe emulsi dilakukan untuk memastikan tidak terjadi inversi fase saat pembuatan basis. Hasil yang didapatkan basis krim tidak larut dalam air, sehingga tipe emulsi dari basis adalah air dalam minyak (A/M).

Pengujian $\mathrm{pH}$ basis dilakukan untuk memastikan bahwa $\mathrm{pH}$ dari krim aman untuk kulit. Hasil yang didapatkan $\mathrm{pH}$ basis krim meningkat saat penyimpanan pada suhu ruang. $\mathrm{pH}$ basis pada formula 1, 2 dan 3 pada hari ke nol sesuai dengan range $\mathrm{pH}$ kulit yaitu 4,5-6,5 [3]. Tetapi saat penyimpanan basis krim pada suhu ruang $\mathrm{pH}$ basis mengalami peningkatan (Lihat Tabel 3). Peningkatan $\mathrm{pH}$ dari basis ini dikarenakan pengaruh dari suhu tempat penyimpanan yang tidak stabil dan juga 
pengaruh adanya bahan lain dalam basis yang ikut bereaksi sehingga $\mathrm{pH}$ basis meningkat. $\mathrm{pH}$ basis masih dalam rentang $\mathrm{pH}$ normal.

Tabel 3. Hasil Uji pH Basis Krim

\begin{tabular}{ccccccc}
\hline \multirow{2}{*}{ Formula } & \multicolumn{5}{c}{ Hari Ke- } & \multirow{2}{*}{ Rata-Rata } \\
\cline { 2 - 5 } & 0 & 7 & 14 & 21 & 28 & \\
\hline I & 6,28 & 7,53 & 7,83 & 7,95 & 7,86 & 7,49 \\
II & 6,10 & 7,66 & 7,93 & 7,90 & 7,19 & 7,35 \\
III & 6,15 & 7,71 & 7,73 & 7,88 & 7,39 & 7,37 \\
IV & 6,70 & 7,77 & 7,78 & 7,65 & 7,61 & 7,50 \\
\hline
\end{tabular}

Viskositas basis krim perlu diperhatikan karena berkaitan dengan kenyamaan penggunaan. Krim harus mudah dioleskan dan dapat menempel pada kulit. Pengujian viskositas basis krim bertujuan untuk mengetahui viskositas (kekentalan) krim. Viskositas merupakan parameter yang menggambarkan tentang besarnya tahanan suatu cairan untuk mengalir. Semakin besar tahanannya, maka viskositas juga akan semakin besar [7].

Tabel 4. Hasil Uji Viskositas Basis Krim

\begin{tabular}{ccccccc}
\hline \multirow{2}{*}{ Formula } & \multicolumn{5}{c}{ Minggu Ke- } & \multirow{2}{*}{ Rata-Rata } \\
\cline { 2 - 6 } & 0 & 1 & 2 & 3 & 4 & \\
\hline I & 0,82094 & 1,16553 & 1,35112 & 0,85665 & 1,10487 & 1,05982 \\
II & 3,85201 & 0,92948 & 0,84867 & 2,14561 & 1,32908 & 1,82097 \\
III & 4,11358 & 1,43786 & 0,92071 & 2,80221 & 2,20973 & 2,29682 \\
IV & 4,99722 & 4,56152 & 6,17283 & 4,50747 & 6,01274 & 5,25036 \\
\hline
\end{tabular}

Hasil yang didapatkan formula basis yang memiliki viskositas yang mendekati viskositas standar sediaan krim yaitu 2-50 Pa.s adalah formula III dan IV. Tetapi viskositas yang paling baik adalah formula IV (Lihat Tabel 4), hal ini juga berhubungan dengan kemampuan daya sebarnya yang mendekati range daya sebar terbaik krim.

Berdasarkan grafik hubungan viskositas dan waktu penyimpanan (Lihat gambar 1), pada penyimpanan basis krim pada formula IV terjadi fluktuasi hasil dimana hal ini dikarenakan faktor suhu ruang yang tidak stabil saat penyimpanan. 


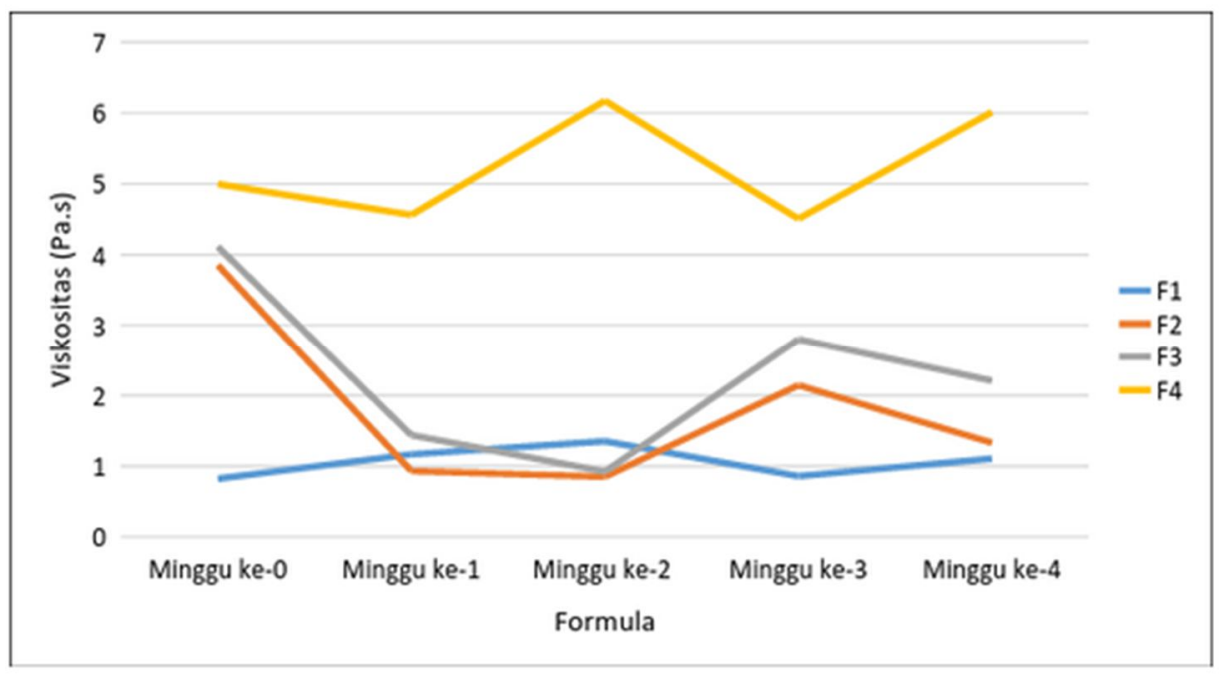

Gambar 1. Hasil Pengujian Viskositas Basis Krim

\section{B. Aktivitas Antioksidan Ekstrak Etil Asetat Daun Cempedak (Artocarpus champeden Spreng)}

Pengujian aktivitas antioksidan ekstrak etil asetat daun cempedak menggunakan metode DPPH. DPPH (1,1- Difenil- 2 - Pikrilhidrazi) merupakan senyawa radikal bebas yang stabil pada suhu kamar, cepat teroksidasi oleh temperatur dan udara [8]. Pengujian antioksidan metode DPPH diawali dengan penentuan panjang gelombang maksimum ( $\lambda$ maks) dan didapatkan $\lambda$ maks larutan DPPH yaitu 515,6 nm.

Aktivitas antioksidan ekstrak ditandai dengan perubahan warna pada larutan DPPH dari ungu menjadi kekuningan. Hal ini dikarenakan larutan DPPH tereduksi menjadi DPPH-H karena adanya donor atom hidrogen [9]. Intensitas warna larutan DPPH kemudian diukur dengan Spektrofotometer UV-Vis sehingga didapatkan nilai absorbansi DPPH.

Tabel 5. Hasil Pengukuran Aktivitas Antioksidan dengan Metode DPPH

\begin{tabular}{ccc}
\hline Konsentrasi $(\mathrm{ppm})$ & Absorbansi & \% Peredaman \\
\hline Blanko & 1,293 & 0 \\
2 & 0,802 & 37,97 \\
4 & 0,665 & 48,57 \\
6 & 0,559 & 56,76 \\
8 & 0,419 & 67,59 \\
10 & 0,259 & 77,18 \\
12 & 0,198 & 84,69 \\
14 & 0,099 & 92,34 \\
16 & 0,059 & 95,44 \\
\hline
\end{tabular}


Peningkatan konsentrasi dari ekstrak berpengaruh terhadap absorbansi DPPH, dimana peningkatan konsentrasi larutan ekstrak mengakibatkan absorbansi dari DPPH menurun (Lihat Tabel 5). Hal ini menandakan terdapat aktivitas antioksidan ekstrak etil asetat daun cempedak terhadap radikal DPPH. Penurunan absorbansi DPPH terjadi karena DPPH telah tereduksi menjadi DPPH-H karena terjadinya donor hidrogen oleh senyawa antioksidan sehingga pada pengukuran dengan Spektrofotometer UV-Vis sinar yang diserap menjadi berkurang karena sinar yang dipancarkan pada $\lambda 515,6 \mathrm{~nm}$ hanya dapat diserap oleh DPPH saja. Sehingga pada perhitungan persen efektivitas selisih absorbansi blanko dengan uji yang digunakan. Hasil yang didapatkan persen peredaman meningkat seiring dengan peningkatan konsentrasi ekstrak etil asetat daun cempedak karena semakin banyak DPPH yang diredam.

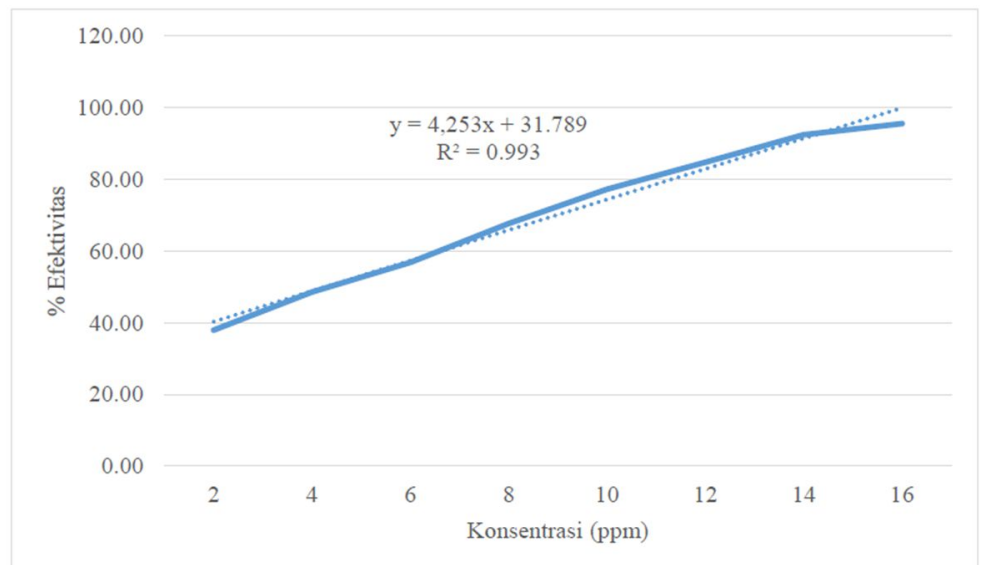

Gambar 2. Kurva Hubungan Konsentrasi dengan \% Efektivitas Larutan Uji

Dari data konsentrasi dan persen efektivitas didapatkan persamaan regresi yaitu $y=4,253 x+31,789$ dengan nilai $r$ sebesar 0,993 (Lihat Gambar 2). Nilai $r$ merupakan nilai yang menyatakan linieritas suatu data dimana nilai $r$ yang mendekati 1 membuktikan bahwa regresi tersebut linier dan menunjukan ketepatan yang cukup tinggi. Persamaan tersebut kemudian digunakan untuk menghitung $\mathrm{IC}_{50}$ dari ekstrak etil asetat daun cempedak. Nilai $\mathrm{IC}_{50}$ yaitu konsentrasi penghambatan sebesar 50\% radikal bebas. Nilai IC 50 yang didapatkan yaitu sebesar 4,282 ppm. Berdasarkan nilai $\mathrm{IC}_{50}$ yang diperoleh dapat disimpulkan ekstrak etil asetat daun cempedak memiliki aktivitas antioksidan yang besar karena dengan konsentrasi 4,282 ppm telah mampu meredam radikal DPPH sebesar 50\%.

\section{KESIMPULAN}

1. Hasil uji optimasi basis diperoleh formula yang memenuhi standar optimal untuk berbagai parameter uji adalah formula IV.

2. Ekstrak etil asetat daun cempedak (Artocarpus champeden Spreng) memiliki aktivitas antioksidan dengan nilai $\mathrm{I}_{\mathrm{C} 50}$ sebesar 4,282 ppm. 


\section{DAFTAR PUSTAKA}

[1] Allen, Loyd V, Nicholas G. P dan Howard C. Ansel. 2011. Ansel's Pharmaceutical Dosage Forms and Drug Delivery System Ninth Edition. Wolters Kluwer: China.

[2] Rhodes, Christopher T. 2002. Modern Pharmaceutics: Fourth Edition, Revised and Expanded. Marcel Dekker Inc: New York.

[3] Fachruddin, L. 1997. Teknologi Tepat Guna Membuat Aneka Selai. Kanisius: Yogyakarta.

[4] Rahmawati, Dwi. 2012. Kandungan Metabolit Sekunder dan Aktivitas Antioksidan Ekstrak Daun dan Kulit Batang Cempedak (Artocarpus champeden Spreng) dengan Metode DPPH. Universitas Mulawarman: Samarinda.

[5] Purwaningsih, Sri. 2012. Aktivitas Antioksidan dan Komposisi Kimia Keong Matah Merah (Cerithidea obtusa). Jurnal Ilmu Kelautan Volume 17 (1) 39-48 ISSN 0853-7291.

[6] Agustin, Rini, Yulida O. dan Henny L. 2013. Formulasi Krim Tabir Surya dari Kombinasi Etil p-Metoksisinamat dengan Katekin. Jurnal Farmasi Universitas Andalas ISSN: 2339-2592.

[7] Sinko, P. J., 2006, Martin's Physical Pharmacy and Pharmaceutical Science: Physical Chemical and Biopharmaceutical Principle in the PharmaceuticalSciences, $5^{\text {th }}$ edition, Lippicott William and Wilkins, Philadelpia.

[8] Yanita. 2011. Penentuan Aktivitas Antioksidan dan Kadar Senyawa Fenolat Total Pada Buah Anggur Merah (Vitis vinifera Linn. Var. Red Globe) dan Anggur Hijau (Vitis vinifera Linn. Var. Chinsiang). Skripsi. Fakultas Farmasi Universitas Andalas Padang.

[9] Wijaya, Abdul Gani. 2011. Uji Aktivitas Antioksidan Fraksi-Fraksi Hasil Pemisahan Ekstrak Etil Asetat Kelopak Bunga Rosella (Hibiscus sabdariffa) dengan Metode Penangkapan Radikal DPPH (2,2 Difenil-1-Pikrilhidrazil). Skripsi. Fakultas Sains dan Teknologi Universitas Islam Negeri Sunan Kalijaga Yogyakarta. 